\title{
Registro de Floresta Ombrófila Mista nas regiões sudoeste e sul do Estado do Paraná, Brasil, durante o Pleistoceno/Holoceno
}

\author{
Édson Bertoldo ${ }^{1,3}$, Julio Cesar Paisani ${ }^{1}$ e Paulo Eduardo de Oliveira ${ }^{2}$
}

Recebido: 5.09.2012; aceito: 2.08 .2013

\begin{abstract}
Araucaria Pine Forest records in southwestern and southern regions of Paraná State, Brazil, during the Pleistocene/ Holocene). Among the forest formations of southern and southeastern of Brazil, the Araucaria Pine Forest is considered one of the most sensitive to climatic variations. Several paleoenvironmental studies try to identify the time at which this type of forest was established in southern Brazil. This paper aims to present the Araucaria Pine Forest records in southwestern and southern Paraná State, from palynological and geochronological data. This study was developed in the State Conservation Unit, Área de Relevante Interesse Ecológico do Buriti, PatoBranco, Paraná State. Frompollen analysis, the presence of 37 taxa was recorded.The record of Araucaria is at least 13,400 years BP (est.), one of the oldest records ever found in the state of Paraná. The expansion of Araucaria and Podocarpus around 4,210 years BP indicates that the climate was cooler and wetter, with well distributed rainfall.

Keywords: Araucaria, palynomorphs, Quaternary

RESUMO - (Registro de Floresta Ombrófila Mista nas regiões sudoeste e sul do do Estado do Paraná, Brasil, durante o Pleistoceno/Holoceno). Dentre as formações florestais do sul e sudeste do Brasil, a Floresta Ombrófila Mista é considerada uma das mais sensíveis às variações climáticas. Vários estudos paleoambientais buscam identificar em que época esse tipo de floresta se estabeleceu no sul do Brasil. Este artigo tem como objetivo apresentar o registro da Floresta Ombrófila Mista na região sudoeste e sul do Estado do Paraná, a partir de dados palinológicos e geocronológicos. Este estudo foi desenvolvido na Unidade de Conservação Estadual Área de Relevante Interesse Ecológico do Buriti, município de Pato Branco, PR, Brasil. $\mathrm{Na}$ análise palinológica foi registrado a presença de 37 táxons, sendo que, o registro de Araucaria é de pelo menos 13.400 anos AP 14C (est.), portanto, um dos registros mais antigos já encontrados no Estado do Paraná. A expansão de Araucaria e Podocarpus em torno de 4.210 anos A.P. indica que o clima era mais frio e mais úmido, com chuvas bem distribuídas. Palavras-chave: Araucária, palinomorfos, Quaternário
\end{abstract}

\section{Introdução}

A superfície do Estado do Paraná, Brasil caracteriza-se por uma diversidade fitogeográfica notável, onde diferentes tipos de florestas ocorrem entremeados por formações herbáceas e arbustivas, resultantes de peculiaridades geomorfológicas, pedológicas e climáticas (Roderjan et al. 2002). As regiões sudoeste (SW) e sul (S) do Estado, assim como grande parte da região sul do Brasil, já foram ocupadas amplamente pela Floresta Ombrófila Mista (ITCF 1991), a qual é considerada uma formação típica do sul do país (Veloso 1992).
A partir do século XX, a exploração madeireira, a substituição da vegetação pela agropecuária e a ampliação das zonas urbanas provocaram a redução da área originalmente ocupada pela Floresta Ombrófila Mista. Estima-se que os remanescentes desse tipo de formação, não perfazem mais do que $0,7 \%$ da área original em território brasileiro (Medeiros et al. 2005).

A associação de Araucaria angustifolia (Bertol.) Kuntze e Podocarpus lambertii Klotzsch ex Eichler é a que melhor representa a paisagem da Floresta Ombrófila Mista (Seibert et al. 1975, Veloso et al. 1991). Essas espécies ocupam as áreas mais baixas das montanhas, podendo ser encontradas acima de

1. Universidade Estadual do Oeste do Paraná, Campus Francisco Beltrão, Rua Maringá, 1200, Vila Nova, 85605-010 Francisco Beltrão, PR, Brasil

2. Universidade São Francisco, Engenharia Ambiental/Gestão Ambiental Av. São Francisco de Assis, s/n, 12900-000, Bragança Paulista, SP, Brasil

3. Autor para correspondência: bertoldo_az@yahoo.com.br 
900 metros de altitude, concentrando-se nos vales, anfiteatros e nas encostas, onde é maior o grau de umidade e os solos estão mais protegidos. Além de ser caracterizada pela grande densidade de $P$. lambertii e A. angustifolia, a Floresta Ombrófila Mista também se destaca pela presença associativa de outras espécies de Lauraceae e Myrtaceae, assim como um número significativo de epífitas, lianas, líquens, musgos e agrupamentos de algumas espécies de pteridófitas nas áreas mais úmidas (Seibert et al. 1975).

A família Araucariaceae possui hoje uma distribuição dominantemente austral, sendo considerada a família de coníferas mais antiga ainda existente, com início de desenvolvimento marcado entre as Eras Paleozóica e Mesozóica (Dutra \& Stranz 2003), sendo que a maior parte de seus representantes modernos vive em florestas úmidas de locais submetidos a clima mesotérmico subtropical ou temperado (Strahler \& Strahler 1989, Nimer 1989).

O processo de sucessão da Floresta Ombrófila Mista está relacionado, principalmente, com a dinâmica populacional de A. angustifolia. Essa espécie é considerada emergente e determinante da fitofisionomia, pois ao colonizar áreas abertas ou campos, cria condições de umidade e fertilidade que facilitam o recrutamento de outras espécies de plantas (Solórzano-Filho \& Kraus 1999). A Floresta Ombrófila Mista é considerada uma das formações florestais mais sensíveis a variações climáticas. Devido a essa característica, diversos estudos paleoambientais buscam identificar em que época esse tipo de formação florestal se estabeleceu no sul do Brasil, já que $A$. angustifolia, é muito seletiva em relação à temperatura e umidade, sendo possível, portanto, correlacionar a sua presença a determinados paleoambientes (Jolly 1998, Lorenzi 2002, Klein 1975).

Este estudo vem ao encontro dessa temática paleoambiental e tem como principal objetivo apresentar o registro da Floresta Ombrófila Mista na região sudoeste e sul do Estado do Paraná, a partir de dados palinológicos e geocronológicos, permitindo também uma aproximação do paleoambiente dessa região a partir da presença de algumas espécies que caracterizam esse tipo de formação florestal.

\section{Material e Métodos}

O presente estudo foi desenvolvido na Unidade de Conservação Estadual denominada Área de Relevante Interesse Ecológico do Buriti (A.R.I.E. do Buriti) que possui 81,5 hectares, e está localizada no município de Pato Branco, região Sudoeste do Estado do Paraná (figura 1). A área de estudo encontra-se a uma altitude de 631 metros e corresponde a uma cabeceira de drenagem.

Por meio de 16 sondagens, utilizando-se trado holandês, foi obtida a distribuição bidimensional

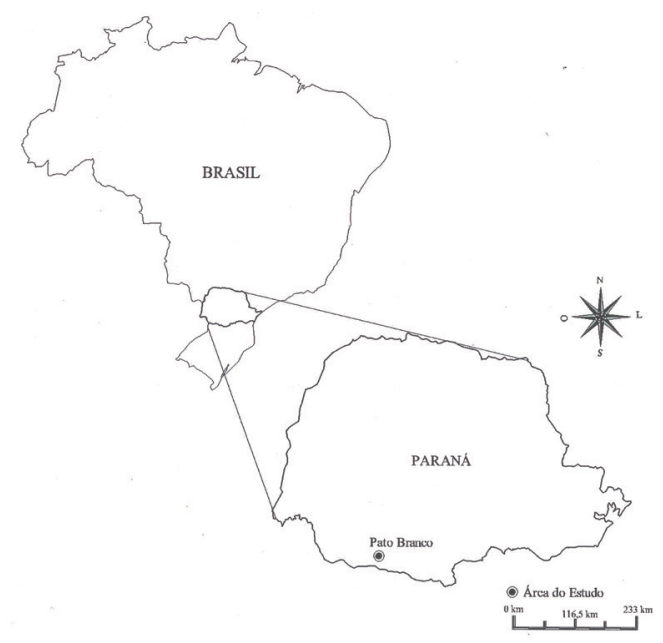

Figura 1. Localização da área de estudo, Área de Relevante Interesse Ecológico do Buriti, município de Pato Branco, PR, Brasil.

Figure 1. Location of the study area, Área de Relevante Interesse Ecológico do Buriti, Municipality of PatoBranco, Paraná State, Brazil.

dos volumes da cobertura superficial da porção central da cabeceira de drenagem ao longo de transecto transversal ao seu eixo central (figura 2), geometricamente designado de hollow (Moura \& Silva 1999).

Após reconstruir a distribuição bidimensional dos volumes da cobertura superficial da porção central da cabeceira de drenagem, foi reconhecido um volume turfoso ao longo do seu eixo central - hollow. O local de maior espessura do volume turfoso foi registrado junto à sondagem 8 (S8). Dessa forma, a sondagem 8 , por apresentar a maior espessura do volume turfoso, foi selecionada para a coleta das amostras.

Assim, nas proximidades do perfil S8 procedeu-se amostragem indeformada do material para análise palinológica. Para essa análise foram coletadas amostras de 0 até $125 \mathrm{~cm}$. Utilizou-se do "amostrador para solos rígidos até sete metros de profundidade" da marca Eikjeilkamp.

O processamento das amostras foi realizado no Laboratório de Palinologia e Paleobotânica Prof. Dr. Murilo Rodolfo de Lima, da Universidade de 
Guarulhos (UnG), Guarulhos - SP, onde foram separadas 26 amostras ao longo dos $125 \mathrm{~cm}$ de profundidade do volume turfoso.

Em cada amostra foi adicionada uma pastilha contendo esporos de Lycopodium clavatum L. cuja concentração era de 18.583 esporos por pílula. Esses esporos são marcadores exóticos que servem para padronizar a contagem e elaborar a estatística palinológica, permitindo o cálculo do número absoluto de grãos por centímetro cúbico de sedimento (Stockmarr 1972).

Todas as etapas do processamento do material obedeceram protocolo descrito no Manual e Atlas Palinológico da Amazônia de Colinvaux et al. (1999), incluindo tratamento com ácido fluorídrico, ácido clorídrico, hidróxido de potássio e acetólise.

Os palinomorfos presentes no material processado foram identificados a partir de comparação com tipos morfológicos dos seguintes trabalhos palinológicos: Erdtman (1952, 1957, 1966), Salgado-Labouriau (1973), Tryon \& Tryon (1982), Roubik \& Moreno (1991), Colinvaux et al. (1999), Lorscheitter et al. (1998, 1999, 2001 e 2002), Fernandes (2009), além da comparação com tipos morfológicos da Palinoteca de Referência do Laboratório de Palinologia e Paleobotânica da UnG. Foram contados no mínimo 300 grãos de pólen de todos os tipos morfológicos, além de outros elementos, como esporos de pteridófitas e algas.

Os tipos polínicos, bem como as algas e esporos de pteridófitas, foram identificados em nível de família, gênero ou às vezes em morfotipos. Esses palinomorfos foram separados de acordo com seus hábitos nas seguintes categorias ecológicas: árvores, arbustos, ervas terrestres, algas e esporos de pteridófitas. A partir desta classificação, os dados foram lançados em um banco de dados do Programa Tilia (Grimm 1987, 1990).

Após identificação e contagem dos palinomorfos, foram elaborados palinodiagramas baseados na porcentagem e concentração de cada tipo de palinomorfo encontrado em cada profundidade do perfil (Salgado-Labouriau 2007). Os palinodiagramas foram gerados a partir dos dados inseridos nos Programas Tilia e TiliaGraph (Grimm 1987, 1990).

Os palinodiagramas de porcentagens de cada táxon foram obtidos com base na soma total de grãos de pólen. Nesta soma foram incluídos tipos polínicos arbóreos, arbustivos, herbáceos (ervas terrestres) e grãos de pólen não identificados. Para efeito de soma de pólen, os esporos e as algas não foram considerados, mas foram somados separadamente, gerando também uma porcentagem própria para essas duas últimas categorias, conforme se verifica nos trabalhos de Palinologia.

Os palinodiagramas de concentração foram gerados, adicionando-se a planilha base do Tilia as seguintes variáveis: número de Lycopodium clavatum contados, número de pílulas (pastilhas) de L. clavatum adicionadas em cada amostra, quantidade de amostra em $\mathrm{cm}^{3}$ e concentração de $L$. clavatum por pílula. $\mathrm{O}$ programa calcula a concentração absoluta de cada palinomorfo por centímetro cúbico de sedimento.

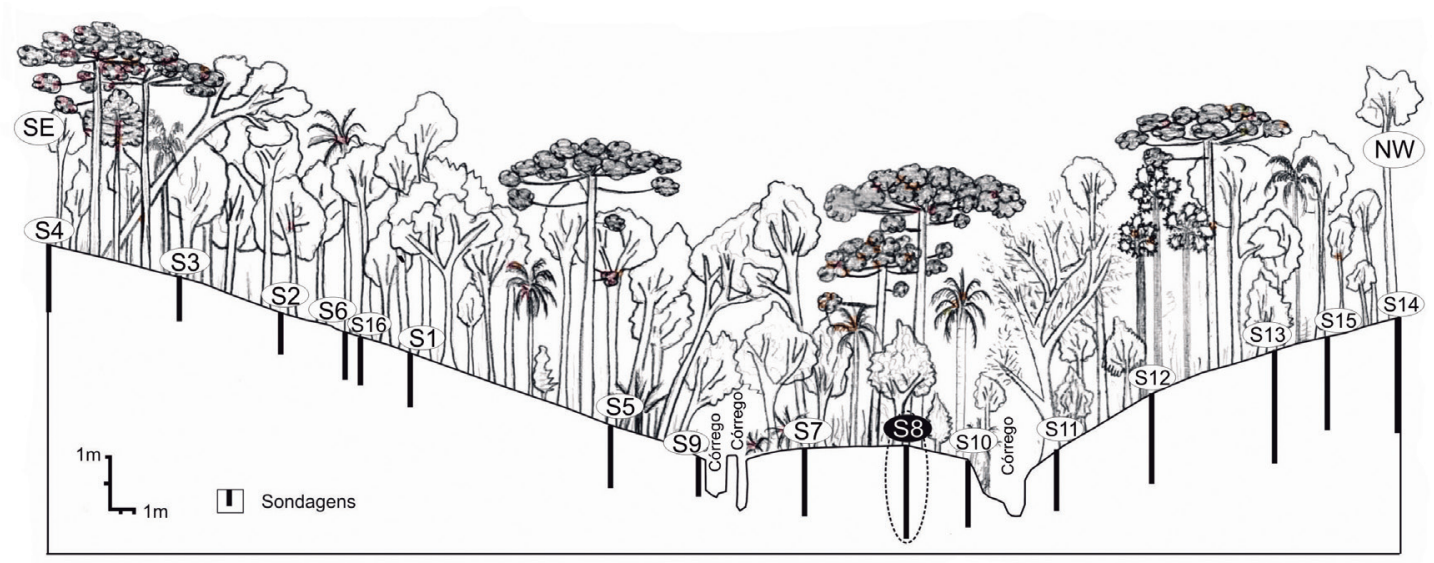

Figura 2. Perfil topográfico transversal à porção central da cabeceira de drenagem estudada, mostrando os locais de sondagens ( 1 1 à S16). Linha descontínua indica o local de coleta de amostras para análise palinológica e datação pelo método do ${ }^{14} \mathrm{C}$. (Adaptado de Paisani et al. 2010)

Figure 2. Topographic profile transverse to the central portion of the studied area ofbedside drainage, showing the locations of probes ( $\mathrm{S} 1$ to S16). Dashed line indicates the location of samples for pollen analysis and ${ }^{14} \mathrm{C}$ dating method. (Adapted from Paisani et al. 2010). 
Diante dos diagramas polínicos optou-se pela coleta de cinco amostras para datação por ${ }^{14} \mathrm{C}$ das profundidades $30-35 \mathrm{~cm}$ (A4), 60-65 $\mathrm{cm}$ (A3), 83-85 cm (A5), 95-100 cm (A2) e 123-125 cm (A6). As amostras A4, A3, A5 e A6 foram devidamente preparadas e encaminhadas para datação, pelo método do ${ }^{14} \mathrm{C}$, ao Laboratório do Carbono 14 do Centro de Energia Nuclear na Agricultura (CENA), USP-Piracicaba. Já a amostra A2 foi encaminhada para datação ${ }^{14} \mathrm{C}$ AMS (accelerator mass spectrometry), ao Laboratório Beta Analytic Inc. (Miami-EUA), conforme tabela 1 .

\section{Resultados e Discussão}

$\mathrm{Na}$ análise palinológica foi registrada a presença de 37 táxons, os quais podem ser observados agrupados em categorias ecológicas na figura $3 \mathrm{e}$ separadamente nas figuras 4 e 5. Alguns táxons são mencionados na literatura como componentes comuns a determinadas unidades fitofisionômicas, como é o caso de Araucaria sp., Podocarpus sp., Ilex sp., Symplocos sp. e Drimys sp., característicos da Floresta Ombrófila Mista (Klein 1975, Behling et al. 2010). Destacam-se também Alchornea sp., Hyeronima sp. e Sloanea sp. como componentes comuns da Floresta Pluvial Atlântica (Lorenzi 2002, Souza \& Lorenzi 2005). Os táxons de Poaceae e Asteraceae são os principais representantes das formações campestres (Souza \& Lorenzi 2005), podendo ocorrer entremeados às formações florestais. Há componentes que são comuns tanto a floresta quanto ao campo, é o caso das Arecaceae e das formações pioneiras, como algumas pteridófitas.

O registro palinológico da A.R.I.E. do Buriti, balizado pela datação, mostra que a espécie Araucaria angustifolia, característica da Floresta Ombrófila Mista, estabeleceu-se na região a pelo menos 13.400 anos A.P. ${ }^{14} \mathrm{C}$ (est.), no final do Pleistoceno, sendo considerado um dos registros mais antigos para essa espécie no Estado do Paraná. É provável que o desenvolvimento máximo dessa espécie tenha ocorrido há aproximadamente 4.210 anos A.P. (final do Holoceno Médio) e se manteve dominante por longo período. No registro polínico, a Araucaria apareceu associada a outras espécies típicas da Floresta Ombrófila Mista, tais como Podocarpus sp., Drymis sp., Ilex sp., Symplocos sp. A expansão significativa de Araucaria e Podocarpus (a aproximadamente 4.210 anos A.P.) sugere que nessa época o clima regional era mais frio e mais úmido.

A revisão bibliográfica realizada apontou que, o paleoambiente da região sul do Brasil, no último ciclo glacial, foi estudado por Behling (2002), em três locais diferentes nos Estados sulinos: Fazenda do Pinto (RS), Morro da Igreja (SC) e Serra dos Campos Gerais (PR), sendo que os resultados sugerem que no passado houve predominância de vegetação de campos, com árvores esparsas de Araucaria na paisagem, onde hoje ocorrem florestas de Araucária e que os campos dominaram a paisagem do sul do Brasil durante o Pleistoceno Superior, onde hoje existem diferentes ecossistemas florestais. Condições climáticas úmidas com nenhum ou apenas curtos períodos de seca, foram

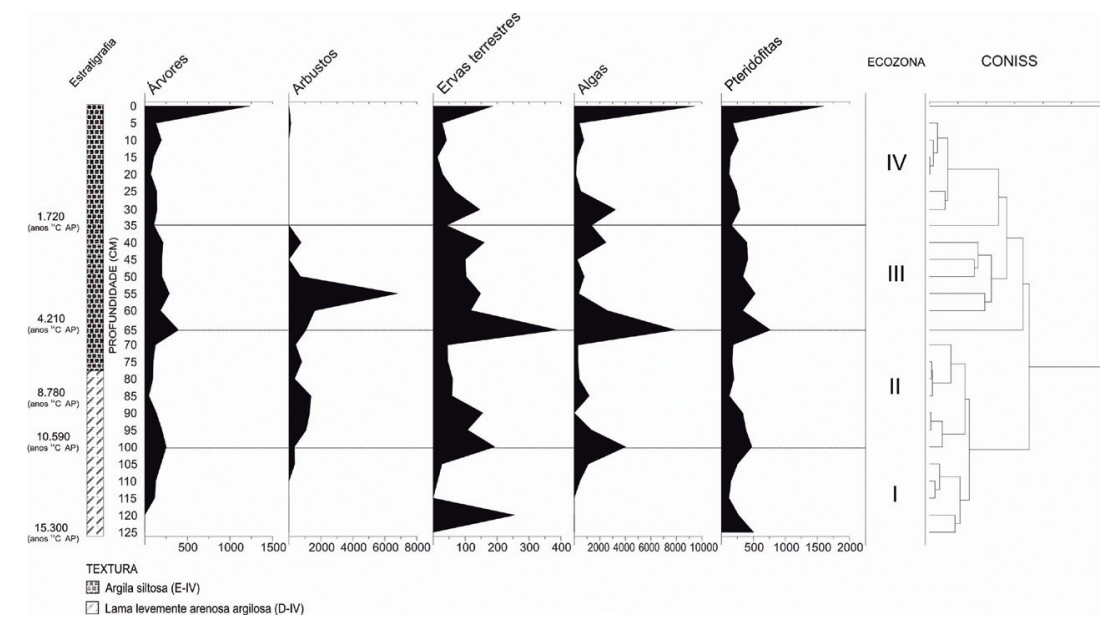

Figura 3. Palinodiagrama de concentração (grãos $\mathrm{cm}^{3}$ ) representando as cinco categorias ecológicas registradas na Área de Relevante Interesse Ecológico do Buriti, município de Pato Branco, PR, Brasil.

Figure 3. Concentration pollen diagram $\left(\right.$ grains $\mathrm{cm}^{3}$ ) representing the five ecological categories registered in Área de Relevante Interesse Ecológico do Buriti, Municipality of PatoBranco, Paraná State, Brazil. 
identificadas pelo autor somente após o Holoceno Superior quando as florestas de Araucária substituíram grandes áreas de vegetação campestre após cerca de 3.000 anos A.P. e especialmente depois de 1.500/1.000 anos A.P.

A existência de campos na regiões sudoeste e sul do Estado do Paraná, como inferida para os

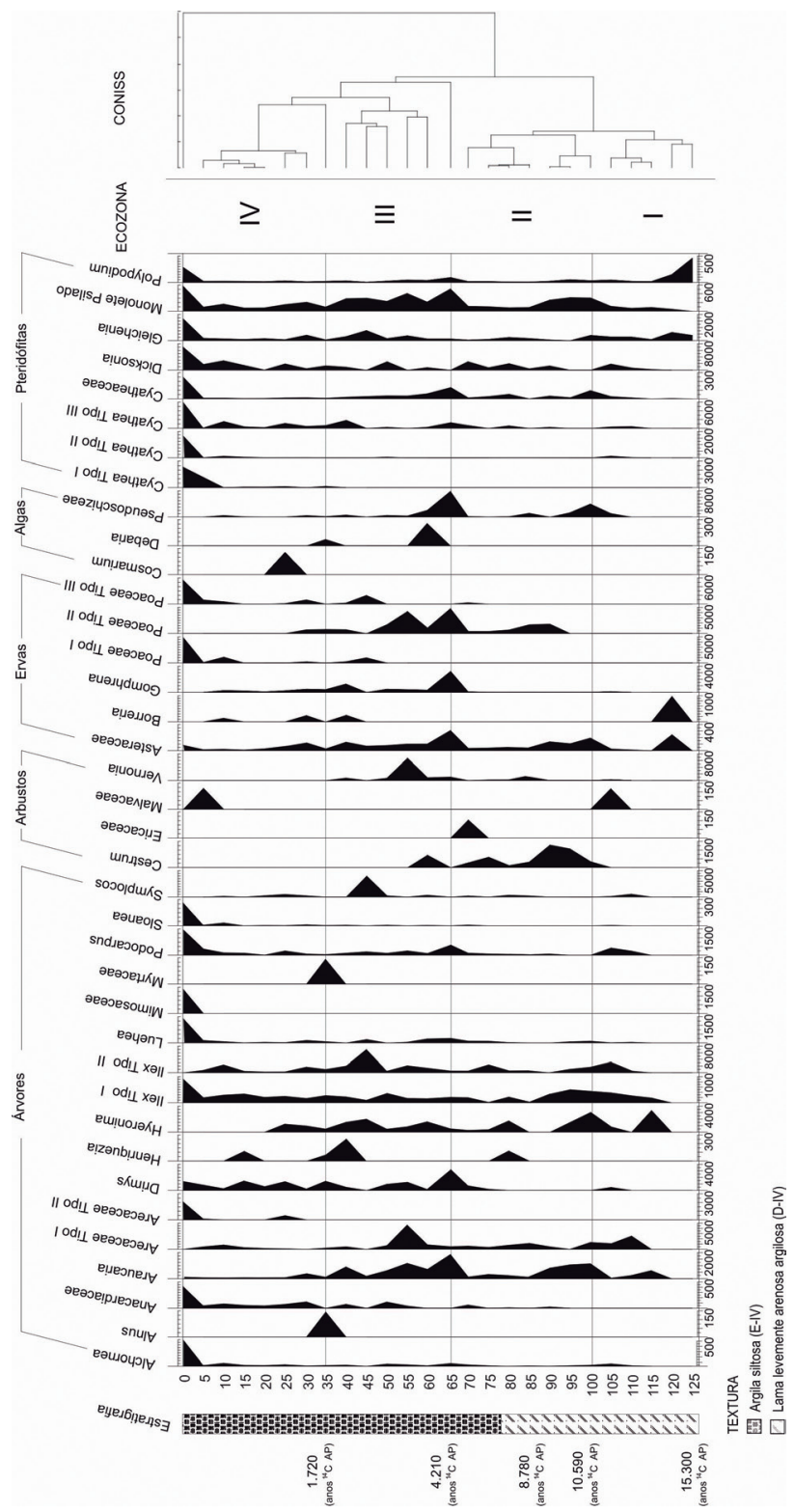

Figura 4. Palinodiagrama de concentração (grãos $\mathrm{cm}^{3}$ ) representando todos os táxons registrados com sua respectiva categoria ecológica ao longo da estratigrafia na Área de Relevante Interesse Ecológico do Buriti, município de Pato Branco, PR, Brasil.

Figure 4. Concentration pollen diagram (grains $\mathrm{cm}^{3}$ ) representing all taxa registered with their respective category along ecological stratigraphy in Área de Relevante Interesse Ecológico do Buriti, Municipality of PatoBranco, Paraná State, Brazil. planaltos sulinos durante o final do Pleistoceno, início e meados do Holoceno (Behling 2002), não é suportada pelos dados obtidos neste trabalho, já que a existência de palinomorfos típicos de formações florestais está presente no perfil da área de estudo desde 13.400 anos A.P. ${ }^{14} \mathrm{C}$ (est.), inferindo que o clima provavelmente não era tão seco a ponto de limitar o

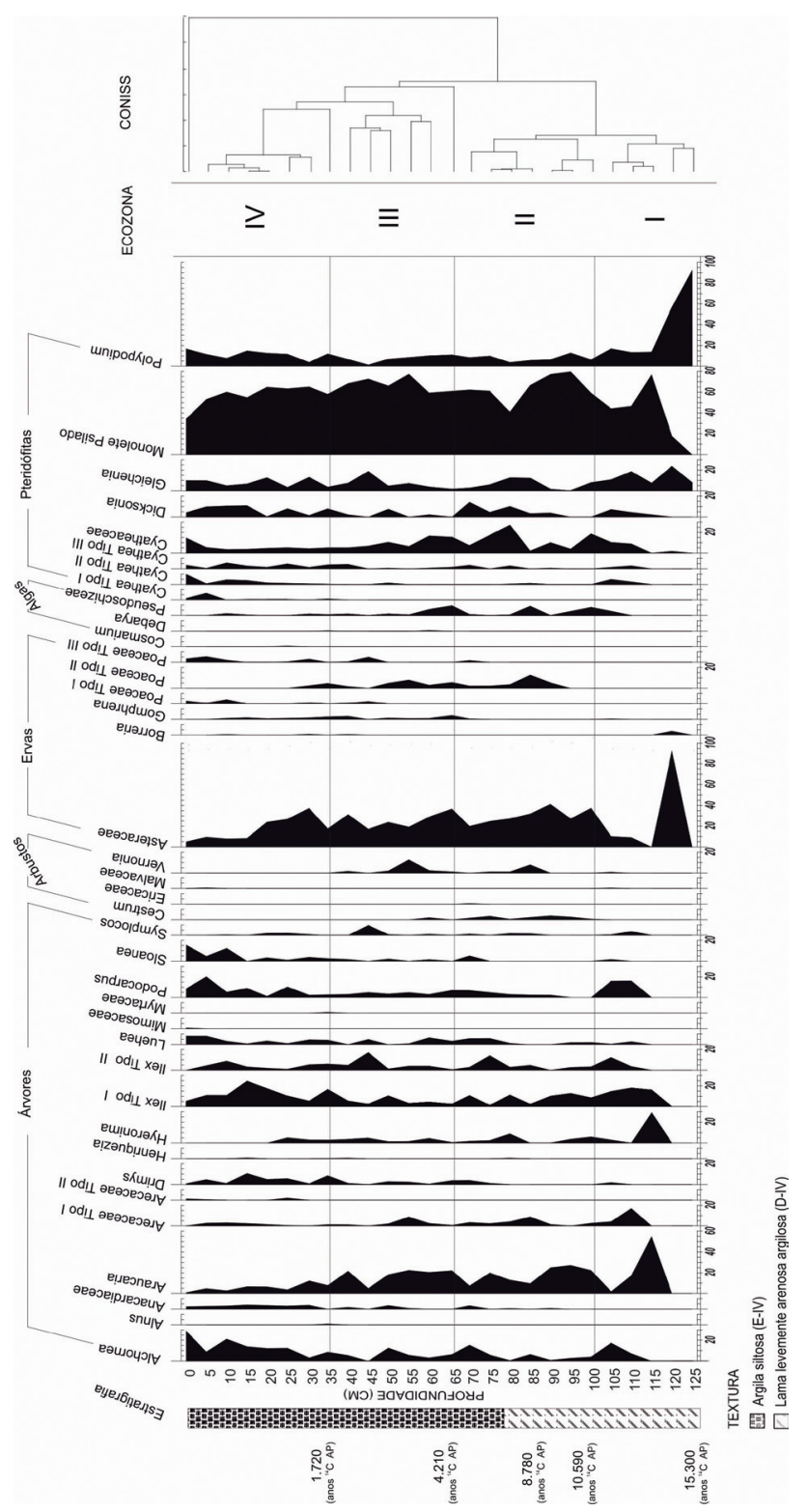

Figura 5. Palinodiagrama de porcentagem (\%) representando os táxons registrados, com sua respectiva categoria ecológica, ao longo da estratigrafia na Área de Relevante Interesse Ecológico do Buriti, município de Pato Branco, PR, Brasil.

Figure 5. Percentage pollen diagram (\%) representing the taxa recorded, with their respective ecological category, along stratigraphy in Área de Relevante Interesse Ecológico do Buriti, Municipality of PatoBranco, Paraná State, Brazil. 
desenvolvimento de espécies arborícolas. Entretanto, é provável que áreas campestres (campos de altitude) estivessem entremeadas com áreas florestadas nas vertentes, assim como na Serra dos Campos Gerais (PR), em que estudos palinológicos (Behling 1997), indicaram que no período entre 12.480 a 9.660 anos A.P., houve predomínio de vegetação de campos, com provável ocorrência de grupos de Araucária nos vales, sugerindo climas mais secos e 3 a $5{ }^{\circ} \mathrm{C}$ mais frios do que o presente.

Estudos desenvolvidos no Terceiro Planalto Paranaense, por Calegari (2008), por meio da análise de resultados isotópicos e fitolíticos na região Centro Oeste do Estado Paraná, constataram mudança na vegetação associada a variações climáticas do Holoceno. Nessa região, antes de 6.730 anos A.P. ${ }^{14} \mathrm{C}$, havia uma mistura de plantas $\mathrm{C}_{3}$ (arbóreas) e $\mathrm{C}_{4}$ (gramíneas), porém com predomínio de $\mathrm{C}_{3}$. Esses resultados também sustentam a idéia da existência de áreas florestadas durante o Holoceno Inferior no Paraná, o que vem ao encontro dos dados levantados neste estudo. Já entre 6.730 e 2.720 anos A.P. ${ }^{14} \mathrm{C}$ (Holoceno Médio), a vegetação apresentava maior contribuição de plantas $\mathrm{C}_{4}$, sugerindo uma vegetação mais aberta (campos) associada a um clima mais seco em relação ao período anterior. De 2.720 anos A.P. ${ }^{14} \mathrm{C}$ até o presente, foi observado novamente um predomínio de plantas $\mathrm{C}_{3}$, marcando a expansão de uma formação florestal mais fechada que evolui até o período atual, para uma Floresta Subtropital Mista com Araucárias. Essa vegetação teria se desenvolvido a partir do Holoceno Inferior $\left(\sim 2000\right.$ anos A.P. $\left.{ }^{14} \mathrm{C}\right)$ associada a um clima mais úmido e, por vezes mais frio, semelhante ao atual.

De acordo com os resultados do presente estudo as espécies típicas da Floresta Ombrófila Mista provavelmente se estabeleceram a pouco mais de 12.000 anos A.P. ${ }^{14} \mathrm{C}$ (est.), ocupando supostas áreas campestres, sugerindo estágios de sucessão ecológica. A partir desse período, a presença de vegetação arbórea foi confirmada até o presente, com momentos de expansão de algumas espécies e retração de outras, como no caso dos táxons Araucaria e Alchornea. Uma expansão muito significativa de todos os táxons de modo geral, a exceção dos arbustos, foi registrada aos $65 \mathrm{~cm}$ de profundidade, que segundo a estimativa da taxa de sedimentação, corresponderia a aproximadamente 6.800 anos A.P ${ }^{14} \mathrm{C}$. Essa idade, segundo a literatura, esta compreendida em uma fase paleoclimática conhecida como Idade Hipsométrica ou Ótimo Climático, estimada entre 9.000 e 2.500 anos A.P. (Deevey Jr \& Flint 1957 apud Suguio 1999) caracterizada por um aumento de temperatura de 1 a $2{ }^{\circ} \mathrm{C}$ em relação a atual. Ainda em relação à melhoria climática, Cortese \& Abelmann (2002), verificaram um resfriamento há 9.000 anos A.P. (abaixo de $15^{\circ} \mathrm{C}$ ) e posteriormente um aumento na temperatura há 7.000 anos A.P. (acima de $17{ }^{\circ} \mathrm{C}$ ). A vegetação teria sido beneficiada por essa variação de temperatura e também por um aumento de umidade nesse período.

\section{Conclusão}

A partir dos resultados obtidos, verificou-se que as regiões sudoeste e sul do Estado do Paraná preservam registros paleoambientais datados do final do Pleistoceno. A presença de espécies típicas da Floresta Ombrófila Mista no perfil pesquisado oportunizou uma aproximação do paleoambiente dessa região nos últimos 13.000 anos AP.

Durante o Holoceno a existência de florestas provavelmente não foi interrompida em escala regional, apresentando-se por vezes mais aberta e por vezes mais fechada, diferente da maioria dos resultados de outros estudos mencionados que mostram a presença predominante de campos no final do Último Máximo Glacial e também durante o Holoceno para o sul do Brasil.

A expansão da Floresta Ombrófila Mista está relacionada a uma mudança para uma forma mais permanentemente úmida, com estações secas mais curtas. A expansão de Araucaria e Podocarpus em torno de 4.210 anos A.P. indica que o clima era mais frio e mais úmido, com chuvas bem distribuídas, já que se tem conhecimento que esses táxons não toleram médias pluviométricas inferiores a $1.400 \mathrm{~mm} / \mathrm{ano}^{-1}$ sendo muito seletivas em relação à temperatura e umidade.

Correlacionando os dados deste trabalho a outros estudos realizados no Estado do Paraná e região sul do Brasil, mencionados anteriormente, verificou-se que as alterações paleoambientais provavelmente são regionais, sendo necessário intensificar as pesquisas paleoecológicas, particularmente as com grãos de pólen e também com dados isotópicos, para melhor interpretarmos a vegetação que existiu no passado, bem como inferir paleoclimas, que certamente nos ajudarão a entender melhor a história da vegetação e do clima da região sul do Brasil. 
Tabela 1. Idade ${ }^{14} \mathrm{C}$ da turfeira analisada na Área de Relevante Interesse Ecológico do Buriti, município de Pato Branco, PR, Brasil.

Table $1 .{ }^{14} \mathrm{C}$ age of the pit analyzedin Área de Relevante Interesse Ecológico do Buriti, Municipality of PatoBranco, Paraná State, Brazil.

\begin{tabular}{ccccc}
\hline $\begin{array}{c}\text { Código do } \\
\text { Laboratório }\end{array}$ & $\begin{array}{c}\text { Código de } \\
\text { Campo }\end{array}$ & $\begin{array}{c}\text { Profundidade das amostras } \\
(\mathrm{cm})\end{array}$ & $\begin{array}{c}\text { Idade Convencional } \\
\left(\text { anos }{ }^{14} \mathrm{C} \mathrm{AP}\right), 1 \delta\end{array}$ & $\begin{array}{c}\text { Idade Calibrada } \\
\left(\text { anos }{ }^{14} \mathrm{C} \mathrm{AP}\right)\end{array}$ \\
\hline CENA 1165 & B-S8-A4 & $30-35$ & $1.720 \pm 80$ & $1.484-1.822$ \\
CENA 1155 & B-S8-A3 & $60-65$ & $4.210 \pm 70$ & $4.525-4.876$ \\
CENA 1156 & B-S8-A5 & $83-85$ & $8.780 \pm 90$ & $9.554-9.964$ \\
BETA 280517 & B-S8-A2 & $95-100$ & $10.590 \pm 40$ & $10.820-10.650$ \\
CENA 1166 & B-S8-A6 & $123-125$ & $15.300+230-220$ & $10.510-10.460$ \\
\hline
\end{tabular}

\section{Agradecimentos}

Ao CNPq (Processo 472267/2009-4) e a Fundação Araucária do Paraná (Convênio 407/2009), pelo apoio financeiro.

\section{Literatura citada}

Behling, H. 1997. Late Quaternary vegetation, climate and fire history in the Araucaria Forest and campos region from Serra dos Campos Gerais Paraná State (South Brazil). Review of Paleobotany and Palynology 97: 109-121.

Behling, H. 2002. South and Southeast Brazilian grasslands during Late Quaternary times: a synthesis. Palaeogeography, Palaeoclimatology and Palaecology 177: 19-27.

Behling, H., Bergamin, R.S., Fidelis, A., JeskePieruschka, V. \& Velez, E. 2010. Araucaria forest dynamics to fire frequency in southern Brazil based on fossil and modern pollen data. Review of Palaeobotany and Palynology 160: 53-65.

Calegari, M.R. 2008. Ocorrência e significado paleoambiental do Horizonte A húmico em Latossolos, SP, Brasil. Tese de Doutorado, Escola Superior de Agricultura Luiz de Queiroz-USP, Piracicaba.

Colinvaux, P., De Oliveira, P.E. \& Moreno, E. 1999. Amazon pollen manual and atlas. Harwood Academic Publishers.

Cortese, G. \& Abelmann, A. 2002. Radiolarianbased paleotemperatures during the last $160 \mathrm{kyr}$ at ODP Site 1089 (Southern Ocean, Atlantic Sector). Palaeogeography, Palaeoclimatology, Palaeoecology 182: 259-286.

Erdtman, G. 1952. Pollen Morphology and Plant Taxonomy. The Chronica Botanica: 1-539.

Erdtman, G. 1957. Pollen and Spore Morphology/ Plant Taxonomy: Gymnospermae, Pterydophyta, Bryophyta (illustrations), an introduction to palinology II. Stockholm: Almqvist \& Wiklsell.
Erdtman, G. 1966. Pollen Morphology and Plant Taxonomy: Angiospermae. New York: Hafner Publishing Company.

Fernandes, R. S. 2009. Reconstrução Paleoambiental da Lagoa Fazenda durante e Neopleistoceno e Holoceno na região de Jussara, Estado do Paraná, com ênfase em Estudos Palinológicos, SP, Brasil. Dissertação de Mestrado. Universidade de Guarulhos, São Paulo.

Grimm, E.C. 1987. CONISS: A Fortran 77 program for stratigraphically constrained cluster analysis by the method of the incremental sumo of squares. Pergamon Journal 13: 13-35.

Grimm, E.C. 1990. Tilia e Tiliagraph: PC spreadsheet and graphics software for pollen data. INQUA. Commission for the study of the Holocene, Working Group on DataHandling Methods Newsletter, 4: 5-7.

ITCF. 1991. Plano de Manejo: A.R.I.E. do Buriti. Instituto de Terras Cartografia e Florestas, Paraná.

Joly, A.B. 1998. Botânica: Introdução à taxonomia vegetal. Companhia Editora Nacional. São Paulo, 12 ed.

Klein, R.M. 1975. Southern Brazilian Phytogeographic Features and Probable Influence of upper Quaternary Climatic Changes in the Floristic Distribution. International Symposium on the Quaternary. Boletim Paranaense de Geociências, n.33.

Lorenzi, H. 2002. Árvores Brasileiras: manual de identificação e cultivo de plantas arbóreas nativas do Brasil. Nova Odessa, SP: Instituto Plantarum, 2 ed, v.1, v.2.

Lorscheitter, M.L., Ashraf, A.R., Bueno, R.M. \& Mosbrugger, V. 1998. Pteridophyte spores of Rio Grande do Sul Flora, Brazil. Part I. Stuttgart: Palaeontographica 246: 1-113.

Lorscheitter, M.L., Ashraf, A.R., Windisch P.G. \& Mosbrugger, V. 1999. Pteridophyte spores of Rio Grande do Sul Flora, Brazil. Part II. Stuttgart: Palaeontographica 251: 1-235. 
Lorscheitter, M.L., Ashraf, A.R., Windisch P.G. \& Mosbrugger, V. 2001. Pteridophyte spores of Rio Grande do Sul Flora, Brazil. Part III. Stuttgart: Palaeontographica 260: 1-165.

Lorscheitter, M.L., Ashraf, A.R., Windisch P.G. \& Mosbrugger, V. 2002. Pteridophyte spores of Rio Grande do Sul Flora, Brazil. Part IV. Stuttgart: Palaeontographica 263: 1-159.

Medeiros, J.D., Savi, M. \& Brito, B. F. A. 2005. Seleção de áreas para criação de Unidades de Conservação na Floresta Ombrófila Mista. Biotemas 18: 33-50.

Moura, J.R.S. \& Silva, T.M. 1999. Complexo de Rampas de Colúvio. In: Cunha, S.B. \& Guerra, A.J.T. Geomorfologia do Brasil, Rio de Janeiro: Bertrand Brasil.

Nimer, E. 1989. Climatologia do Brasil. 2 ed. IBGE. Rio de Janeiro.

Paisani, J.C. Bertoldo, E., Pontelli, M.E., Guerra, S., Oliveira, L. \& Lima, J.G.G. 2010. Caracterização das Formações Superficiais do hollow de Cabeceria de Drenagem na A.R.I.E. do Buriti - Planalto Basáltico (Pato Branco - PR).

Roubik, D.W. \& Moreno P.J.H. 1991. Pollen and Spores of Barro Colorado Island. Monographs in Systematic Botany36. USA: Missouri Botanical Garden: 1-268.

Roderjan, C.V. Galvão, F., Kunovoshi, Y. S. \& Hatschbach, G.G. 2002. As Unidades Fitogeográficas do Estado do Paraná. Ciência e Ambiente 24.
Salgado-Labouriau, M.L. 1973. Contribuição à Palinologia dos Cerrados. Rio de Janeiro: Academia Brasileira de Ciências: 1-291.

Salgado-Labouriau, M.L. 2007. Critérios e Técnicas para o Quaternário. São Paulo: Edgard BLücher.

Seibert, P. \& Carauta, J.P.P. 1975. Plano de Manejo do Parque Estadual de Campos do Jordão. Boletim Técnico do Instituto Florestal 19: 1-153.

Solórzano-Filho, J.A. \& Kraus, J.E. 1999. Breve história das matas de Araucária. Forest 99: 37-47.

Souza, V.C. \& Lorenzi, H. 2005. Botânica Sistemática: Guia Ilustrado para identificação das famílias de Angiospermas da flora brasileira, baseado em APG II. Nova Odessa, SP: Instituto Plantarum, pp. 1-640.

Stockmarr, J. 1972. Tablets with spores used in absolute pollen analysis. Pollen et spores 13.

Strahler, A.N. \& Strahler, A.H. 1989. Elements of Physical Geography. John Wiley ans Sons. New York.

Suguio, K. 1999. Geologia do Quaternário e mudanças ambientais. São Paulo: Paulo’s Comunicação e Artes Gráficas.

Tryon, R.M. \& Tryon, A.F. 1982. Ferns and Allied Plants with special reference to tropical America. SpringerVerlag. New York. Heidelverg. Berlin.

Veloso, H. P., Rangel Filho, A.L.R. \& Lima, J.C.A. 1991. Classificação da vegetação brasileira adaptada a um sistema universal. IBGE. Rio de Janeiro.

Veloso, H.P. 1992. Sistema fitogeográfico. In: H.P. Veloso (org.). Manual técnico da vegetação brasileira. Instituto Brasileiro de Geografia e Estatística, Rio de Janeiro. 